\title{
Ferramenta gratuita para projetos sustentáveis: estudo de caso em laboratórios públicos de pesquisa em saúde
}

\author{
Free tool for sustainable design projects: case study on \\ health research public laboratories
}

\author{
Marcia Castilho Correia \\ Bianca Marques Figueiredo Leal \\ Leopoldo Eurico Gonçalves Bastos
}

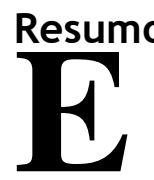

ifícios para laboratórios de pesquisa em saúde necessitam atende às regulamentações edilícias e a normas de biossegurança, conforme o tipo de laboratório proposto. No Brasil, a Fundação Oswaldo Cruz (Fiocruz), um centro de referência em pesquisas em saúde, tem desenvolvido projetos que contemplam questões voltadas para a sustentabilidade. Revela-se uma tarefa difícil conjugar os requisitos de sustentabilidade para as edificações públicas com as imposições de biossegurança. $\mathrm{O}$ presente artigo visa investigar sobre o potencial de uso de uma ferramenta gratuita de avaliação de sustentabilidade no ambiente construído em projetos de laboratórios para pesquisa em saúde, que usualmente ocupam edificações públicas, e ainda considerar o atendimento aos requisitos da biossegurança, através de uma abordagem baseada em evidências. Para isso, utilizou-se um estudo de caso de um projeto para edificação laboratorial da Fiocruz que requer requisitos de segurança biológica de risco NB-3 e de sustentabilidade através da ferramenta de avaliação gratuita SBTool. A matriz de análise resultante indica que os ditames da biossegurança trazem restrições à concepção do projeto de laboratórios e ainda impõem limitações para a sustentabilidade. Apesar de algumas restrições, a ferramenta proposta poderá reduzir os gastos públicos com certificações comerciais.

Palavras-chave: Projeto de edifícios públicos. Laboratório de pesquisa em saúde. Biossegurança. Avaliação de sustentabilidade.

\section{Abstract}

1, 2 Marcia Castilho Correia ${ }^{1}$ Fundação Oswaldo Cruz Rio de Janeiro - RJ - Brasil ${ }^{2}$ Universidade Federal do Rio de Janeiro Rio de Janeiro - RJ - Brasil

${ }^{3}$ Bianca Marques Figueiredo Leal ${ }^{3}$ Universidade Federal do Rio de Janeiro

Rio de Janeiro - RJ - Brasil

${ }^{4,}{ }^{5}$ Leopoldo Eurico Gonçalves Bastos

${ }^{4}$ Universidade Federal do Rio de Janeiro

Rio de Janeiro - RJ - Brasil ${ }^{5}$ Universidade Vila Velha Vila Velha - ES - Brasil

Recebido em 08/07/19 Aceito em 26/05/20
Health research laboratory buildings need to comply with building regulations and biosafety standards, according to the type of laboratory proposed. In Brazil, the Oswaldo Cruz Foundation (Fiocruz), a reference center in health research, has been developing projects that address issues related to sustainability. It has proven to be a difficult task to combine sustainability requirements for public buildings with biosafety requirements. This article aims to investigate the potential use of a free tool for assessing sustainability in the built environment of health research laboratory installations, which are usually located in public buildings, as well as to examine to what extent these installations meet biosafety requirements, through an evidence-based approach. In order to do this, the researchers used the case study of a design for a laboratory building of Fiocruz that must meet biological safety requirements of risk NB-3 and sustainability through the free evaluation SBTool. The resulting analysis matrix indicates that the dictates of biosafety bring restrictions to the design of the laboratory installations and still impose limitations for sustainability. Despite some restrictions, the proposed tool may reduce public spending on commercial certifications.

Keywords: Public buildings design project. Health research laboratory. Biosafety. Sustainability assessment.

CORREIA, M. C.; LEAL, B. M. F.; BASTOS, L. E. G. Ferramenta gratuita para projetos sustentáveis: estudo de caso em laboratórios públicos de pesquisa em saúde. Ambiente Construído, Porto Alegre, v. 21, n. 1, p. 217-236, jan./mar. 2021. 


\section{Introdução}

Edifícios para laboratórios de pesquisa em saúde têm requisitos próprios, pois necessitam atender às regulamentações edilícias e às recomendações específicas como as definidas pela Anvisa e pela Organização Mundial de Saúde, entre outros órgãos. Essas edificações demandam projetos específicos, dotados de complexidades definidas pelo requerido grau de biossegurança. A relevância da pesquisa em saúde para a sociedade ficou mais evidente com o esforço mundial para o enfrentamento de epidemias como a recente do coronavírus SARS-CoV-2 ou COVID-19. O processo de pesquisa é fundamental, pois possibilita identificar, isolar e controlar a mortalidade dos primeiros casos (DOMINGUEZ..., 2020). São as edificações laboratoriais que oferecem a infraestrutura adequada para que sejam realizados experimentos com a segurança necessária.

Esses laboratórios, além da problemática da biossegurança, devem atender a legislação brasileira e as normas de eficiência energética (BRASIL, 2014), pois todos os projetos e obras de construções públicas são obrigatoriamente norteados pelos princípios da sustentabilidade (BRASIL, 1988, 1993, 2010, 2012). Segundo Correia (2019), os princípios de sustentabilidade dizem respeito aos processos de extração ou fabricação, utilização e descarte dos produtos e matérias-primas, ao longo de todo o ciclo de vida, desde os materiais de construção. $\mathrm{O}$ autor ainda cita que as especificações e demais exigências dos projetos devem visar à economia da manutenção e operacionalização da edificação, a redução do consumo de energia e água, bem como a utilização de tecnologias e materiais que reduzam o impacto ambiental. O conceito legal de sustentabilidade abrange o tripé completo, conforme as diretrizes de sustentabilidade regulamentadas pelo Decreto Federal n. 7.746 (BRASIL, 2012) e explicitadas no Quadro 1.

Os projetos públicos devem também atender aos princípios da legalidade, impessoalidade, isonomia, moralidade, publicidade, eficiência, probidade administrativa, celeridade no âmbito judicial e administrativo. Adicionalmente ainda deve prevalecer a economia e o interesse público, buscando tornar a Administração Pública mais eficiente (BRASIL, 1988). Porém, para garantir a contenção de contaminantes para os laboratórios são necessários instalações e equipamentos de alto custo e elevado consumo energético.

Com relação à eficiência energética, em 2014 a Instrução Normativa n. 2/2014 (BRASIL, 2014), do Ministério do Planejamento, Orçamento e Gestão (MPOG), passou a exigir o uso da Etiqueta Nacional de Conservação de Energia (ENCE), em seu nível mais alto, classe "A”, nos projetos e edificações públicas federais que receberam retrofit ou em novas construções. $\mathrm{O}$ foco da ENCE é apenas a eficiência energética e não a certificação de sustentabilidade, processo mais amplo e complexo.

Importante destacar que a legislação brasileira não exige nenhuma certificação de sustentabilidade, apesar da obrigatoriedade de atendimento aos princípios de sustentabilidade nos projetos de construções públicas. Portanto, poderia ser utilizada alguma ferramenta gratuita para avaliar a sustentabilidade e reduzir os gastos públicos com certificações comerciais, podendo ser o SBTool, o PROJETEEE (BRASIL, 2020) ou outra como a ferramenta proposta na tese de doutorado por Correia (2019).

Quadro 1 - Diretrizes governamentais para projetos sustentáveis

\begin{tabular}{|c|l|l|}
\hline \multicolumn{2}{|c|}{ Diretrizes governamentais de sustentabilidade } & \multicolumn{1}{c|}{ Impacto } \\
\hline I & $\begin{array}{l}\text { Menor impacto sobre recursos naturais como flora, fauna, ar, solo e } \\
\text { água }\end{array}$ & Ambiental \\
\hline II & Preferência por materiais, tecnologias e matérias-primas de origem local & Econômico e social \\
\hline III & Maior eficiência na utilização de recursos naturais como água e energia & Ambiental \\
\hline IV & Maior geração de empregos, preferencialmente com mão de obra local & Econômico e social \\
\hline V & Maior vida útil e menor custo de manutenção do bem e da obra & Econômico e social \\
\hline VI & Uso de inovações que reduzam a pressão sobre recursos naturais & Ambiental \\
\hline VII & $\begin{array}{l}\text { Origem ambientalmente regular dos recursos naturais utilizados nos } \\
\text { bens, serviços e obras }\end{array}$ & Ambiental \\
\hline
\end{tabular}

Fonte: Correi Decreto Federal n. 7.746 de $2012^{1}$.

${ }^{1} \mathrm{O}$ Decreto Federal n. 7.746 de 2012 regulamenta o artigo $3^{\circ}$ da Lei das Licitações e estabelece, de forma complementar, diretrizes para a promoção do desenvolvimento nacional sustentável. 
Em complemento, torna-se ainda necessário atender à IN n. 5/2017 (BRASIL, 2017), que recomenda a realização de análises de viabilidade econômico-financeira, do retorno do investimento e de riscos do empreendimento, consumando a avaliação de sustentabilidade.

Fenili (2016) considera as licitações sustentáveis como não consolidadas, indicando que, em geral, os principais problemas relacionados a elas estão ligados a questões de gestão de conhecimento sobre a sustentabilidade. Além de um contexto legal de normas esparsas e fragmentadas, há requisitos ambientais específicos a serem observados nos objetos licitados.

A obediência aos critérios para etiquetagem ENCE e de sustentabilidade interfere diretamente nos projetos, nas especificações de materiais e sistemas a serem utilizados nas edificações, sendo fundamental que os conceitos sejam incorporados desde a concepção do projeto.

Acredita-se que uma avaliação dos requisitos de sustentabilidade por meio de uma ferramenta acessível e gratuita poderá equalizar os procedimentos atualmente realizados e ainda reduzir os gastos públicos com certificações. Assim, o objetivo deste trabalho é avaliar o uso de uma ferramenta gratuita de avaliação de sustentabilidade em projeto arquitetônico de laboratórios para pesquisa em saúde, que usualmente ocupam edificações públicas, atendendo simultaneamente aos requisitos da biossegurança.

A metodologia compreende a pesquisa de fontes bibliográficas, relacionando os requisitos de biossegurança com os de sustentabilidade, através de uma abordagem baseada em evidências avaliadas pelos autores (HAMILTON; MCCUSKEY SHEPLEY, 2016). Além dessa avaliação, propõe-se o emprego de uma ferramenta gratuita para avaliação da sustentabilidade, através de um estudo de caso de um projeto para novos laboratórios da Fiocruz a ser construído em Minas Gerais.

\section{Especificidades de projetos de laboratórios de pesquisa em saúde}

Todo arquiteto para projetar adequadamente uma edificação precisa se informar sobre a proposta e conhecer bem as funções da edificação (BICALHO, 2010). Para realizar projetos de laboratórios na área de saúde é necessário o conhecimento de critérios bem específicos e que variam segundo a especificidade de pesquisa a ser desenvolvida.

Devido aos distintos riscos envolvidos nas atividades laboratoriais, algumas áreas precisam impedir que contaminantes entrem, enquanto em outras deve haver uma contenção para impedir que patógenos saiam e contaminem pessoas e o meio ambiente em geral (DIBERARDINIS et al., 2013).

\section{Biossegurança}

A instalação e a operação de laboratórios de pesquisa em saúde requerem a realização periódica de processos de gerenciamento de riscos orientados para a avaliação, controle, comunicação e revisão dos riscos à qualidade e à segurança.

Os níveis de risco e de biossegurança em vigor estão indicados no Quadro 2, que permite o entendimento geral do enquadramento estabelecido.

Diversos fatores podem ainda se somar na classificação dos níveis de risco à saúde e bem-estar dos homens, animais e ao meio ambiente em geral, com relação aos patógenos, agentes biológicos e produtos químicos envolvidos. Além do grau de patogenicidade para os seres vivos, o modo de transmissão, o raio de ação e a existência de medidas de prevenção também são levados em conta.

\section{Instalações e equipamentos: condições de projeto e operação}

A escolha das instalações físicas e dos equipamentos para um laboratório de pesquisa em saúde é realizada em função das atividades a serem realizadas, dos protocolos e dos níveis exigidos de segurança biológica. $\mathrm{O}$ Quadro 3 apresenta uma classificação dos requisitos essenciais para área física e instalações, indicando os que são recomendados $(\mathrm{R})$ ou obrigatórios $(\mathrm{O})$ conforme o nível de biossegurança do local.

Alguns equipamentos demandam instalações especiais (gases, antivibração, etc.).

O posicionamento dos equipamentos no laboratório deve atender questões de segurança e da sequência dos procedimentos a serem realizados, de forma a impedir cruzamentos de fluxos, nem interferência no uso dos equipamentos.

As instalações físicas e os equipamentos devem ser projetados, construídos e instalados para facilitar seu 
funcionamento e proporcionar uma fácil manutenção, limpeza, descontaminação e testes de certificação, obedecendo a um gradiente de segurança, separando os fluxos e as atividades a serem desenvolvidas no laboratório, conforme o nível de biossegurança indicado (ORGANIZAÇÃO..., 2004, 2013), e sem dispensar a qualidade do ambiente, o conforto e a preservação da saúde (CORREIA, 2019).

Os equipamentos podem ser de uso recomendado ou obrigatório, como mostra o Quadro 4.

Constituem-se os equipamentos em: de armazenamento, de manipulação, ou de contenção. Os freezers são exemplos de equipamentos de armazenamento.

Os equipamentos de manipulação podem potencializar o risco de contaminação, como é o caso dos equipamentos que realizam amplificação, centrifugação ou ainda sonicação, que é um procedimento que utiliza a energia das ondas sonoras, usualmente ultrassom.

O termo "contenção" diz respeito aos procedimentos de biossegurança utilizados na manipulação de agentes. Dessa forma, os equipamentos de contenção são concebidos para prevenir ou limitar o contato entre o material infeccioso, o operador e o meio ambiente. Conforme o caso, são indicados diferentes posicionamentos e tipos de autoclaves (para esterilizações diversas), cabines de segurança biológica, cabines de exaustão química, cabine de fluxo laminar, câmara pressurizada de passagem (passthrough), etc.

As cabines de segurança biológica e as cabines de exaustão química devem ser instaladas de forma que as flutuações de ar da sala não interfiram em seu funcionamento e, portanto, devem se distanciar das portas, tomadas de ar dos sistemas de condicionamento de ar e das áreas de circulação.

A incineração é útil para o descarte de resíduos de laboratório, mas exige meios eficientes de controle de temperatura e uma câmara de combustão secundária. A autoclavagem é mais eficiente energeticamente e ambientalmente, porém devem ser usadas autoclaves separadas para esterilizar soluções ou vidraria (material limpo) e para descontaminar materiais infecciosos (ORGANIZAÇÃO..., 2013).

A desinfecção por ação química, alternativa de controle e contenção, depende da concentração usada, do tempo de contato e da presença ou não de resíduos orgânicos (ORGANIZAÇÃO..., 2013).

Quadro 2 - Relação entre níveis de biossegurança e de risco

\begin{tabular}{|c|c|c|c|}
\hline $\begin{array}{l}\text { Classes } \\
\text { de risco }\end{array}$ & $\begin{array}{c}\text { Níveis de } \\
\text { biossegurança }\end{array}$ & Níveis de risco & Tipo de laboratório \\
\hline 1 & $\begin{array}{l}\text { NB-1 } \\
\text { Básico }\end{array}$ & $\begin{array}{l}\text { Nenhum risco ou } \\
\text { baixo risco } \\
\text { individual e } \\
\text { comunitário }\end{array}$ & $\begin{array}{l}\text { Laboratórios básicos de ensino e pesquisa } \\
\text { Nível adequado à manipulação de agentes } \\
\text { biológicos conhecidos por não causarem doenças } \\
\text { em adultos sadios. }\end{array}$ \\
\hline 2 & $\begin{array}{l}\text { NB-2 } \\
\text { Básico }\end{array}$ & $\begin{array}{l}\text { Risco individual } \\
\text { moderado e risco } \\
\text { comunitário } \\
\text { limitado (baixo a } \\
\text { moderado) }\end{array}$ & $\begin{array}{l}\text { Laboratórios clínicos; laboratórios de serviços } \\
\text { de diagnóstico e pesquisa } \\
\text { Nível adequado à manipulação dos agentes } \\
\text { biológicos cujos riscos individuais são moderados e } \\
\text { para a comunidade é baixo. O risco de propagação } \\
\text { é limitado. }\end{array}$ \\
\hline 3 & $\begin{array}{c}\text { NB-3 } \\
\text { Contenção }\end{array}$ & $\begin{array}{l}\text { Alto risco } \\
\text { individual e baixo } \\
\text { risco coletivo }\end{array}$ & $\begin{array}{l}\text { Laboratórios de diagnóstico e pesquisa especiais } \\
\text { Nível adequado à manipulação dos agentes } \\
\text { biológicos com potencial para transmissão por via } \\
\text { aérea e a causarem patologias potencialmente } \\
\text { letais, para as quais existem usualmente medidas de } \\
\text { tratamento e/ou de imunização. }\end{array}$ \\
\hline 4 & $\begin{array}{l}\text { NB-4 } \\
\text { Contenção } \\
\text { máxima }\end{array}$ & $\begin{array}{l}\text { Alto risco } \\
\text { individual e } \\
\text { coletivo }\end{array}$ & $\begin{array}{l}\text { Laboratórios clínicos; laboratórios de serviços } \\
\text { de diagnóstico e pesquisa } \\
\text { Nível adequado à manipulação dos agentes } \\
\text { biológicos exóticos ou perigosos, com alto poder de } \\
\text { transmissão por via respiratória ou desconhecida e } \\
\text { alta letalidade. Sem profilaxia ou terapêutica } \\
\text { eficiente. }\end{array}$ \\
\hline
\end{tabular}

Fonte: Correia e Leal (2016). 
Quadro 3 - Requisitos para área física e instalações recomendados (R) ou obrigatórios (0) conforme níveis de biossegurança

\begin{tabular}{|c|c|c|c|c|}
\hline Resumo dos Requisitos & NB1 & NB2 & NB3 & NB4 \\
\hline Sinalização com símbolo de risco biológico & $\mathrm{R}$ & $\mathrm{O}$ & $\mathrm{O}$ & $\mathrm{O}$ \\
\hline Laboratório separado de passagens públicas & $\mathrm{R}$ & $\mathrm{O}$ & $\mathrm{O}$ & $\mathrm{O}$ \\
\hline Laboratório com acesso controlado & $\mathrm{R}$ & $\mathrm{O}$ & - & - \\
\hline Laboratório com acesso restrito & - & - & $\mathrm{R}$ & $\mathrm{O}$ \\
\hline Local para armazenar jalecos e EPIs no laboratório & $\mathrm{R}$ & $\mathrm{R}$ & $\mathrm{O}$ & $\mathrm{O}$ \\
\hline Lavatório para mãos próximo à entrada/saída do laboratório & $\mathrm{O}$ & $\mathrm{O}$ & $\mathrm{O}$ & $\mathrm{O}$ \\
\hline Torneira com acionamento sem o uso das mãos & - & $\mathrm{R}$ & $\mathrm{O}$ & $\mathrm{O}$ \\
\hline Ventilação: fluxo interno de ar & - & $\mathrm{R}$ & $\mathrm{O}$ & $\mathrm{O}$ \\
\hline Ventilação: sistema central de ventilação & - & $\mathrm{R}$ & $\mathrm{O}$ & $\mathrm{O}$ \\
\hline Ventilação: exaustão com filtragem HEPA*** & - & - & $\mathrm{O}$ & $\mathrm{O}$ \\
\hline Ventilação com sistema de suporte de vida para EPI & - & - & - & $\mathrm{O}$ \\
\hline Laboratório com janelas vedadas & - & $\mathrm{R}$ & $\mathrm{R}$ & - \\
\hline Laboratório sem janelas & - & - & $\mathrm{R}$ & $\mathrm{O}$ \\
\hline Pressão negativa & - & - & $\mathrm{O}$ & $\mathrm{O}$ \\
\hline Antecâmara & - & - & $\mathrm{O}$ & - \\
\hline Antecâmara com lavatório e local para jalecos & - & $\mathrm{R}^{*}$ & $\mathrm{R}^{*}$ & - \\
\hline Antecâmara dotada de portas com intertravamento & - & - & $\mathrm{O}$ & $\mathrm{O}$ \\
\hline Antecâmara com chuveiro & - & - & $\mathrm{R} *$ & - \\
\hline Antecâmara pressurizada com chuveiro & - & - & - & $\mathrm{O}$ \\
\hline Paredes, tetos e piso lisos, impermeáveis e resistentes & $\mathrm{R}$ & $\mathrm{O}$ & $\mathrm{O}$ & $\mathrm{O}$ \\
\hline Tratamento de efluentes & - & - & $\mathrm{R}^{*}$ & $\mathrm{O}$ \\
\hline Sistema de geração de emergência energia elétrica & - & $\mathrm{R}^{*}$ & $\mathrm{O}$ & $\mathrm{O}$ \\
\hline Selagem/vedação de frestas nas paredes, tetos, piso, etc. & - & - & $\mathrm{O}$ & $\mathrm{O}$ \\
\hline Cabine de segurança biológica & - & $\mathrm{R}^{* *}$ & $\mathrm{O}$ & $\mathrm{O}$ \\
\hline Autoclave próxima ao laboratório & $\mathrm{R}$ & $\mathrm{O}$ & $\mathrm{O}$ & - \\
\hline Autoclave dentro do laboratório & - & - & $\mathrm{R}$ & $\mathrm{O}$ \\
\hline Autoclave dupla porta & - & - & $\mathrm{R}$ & $\mathrm{O}$ \\
\hline Monitoração de segurança (visor, CFTV, interfone, etc.) & - & - & $\mathrm{R}$ & $\mathrm{O}$ \\
\hline Facilidade de limpeza, descontaminação e manutenção & $\mathrm{O}$ & $\mathrm{O} *$ & O* & $\mathrm{O}^{*}$ \\
\hline
\end{tabular}

Fonte: Correia (2019).

Nota: *adoção de barreiras adicionais conforme avaliação do risco biológico.

**obrigatória nos casos de geração de aerossóis.

***sistema de filtragem absoluta de ar (High Efficiency Particulate Air - HEPA)

\section{Quadro 4 - Equipamentos recomendados $(R)$ ou obrigatórios $(0)$ conforme níveis de biossegurança}

\begin{tabular}{|l|c|c|c|c|}
\hline \multicolumn{1}{|c|}{ Boas práticas e equipamentos a serem instalados } & NB1 & NB2 & NB3 & NB4 \\
\hline Lava-olhos disponível & R & O & O & O \\
\hline Trabalho em cabine de segurança biológica (CSB) tipo I (sem exaustão própria) & $\mathrm{R}$ & - & - & - \\
\hline $\begin{array}{l}\text { Trabalho em cabine de segurança biológica tipo II (com filtração HEPA de ar } \\
\text { emergente) }\end{array}$ & $\mathrm{R}$ & $\mathrm{O}$ & $\mathrm{O}$ & - \\
\hline $\begin{array}{l}\text { Trabalho em cabine de segurança biológica tipo II (com 100\% exaustão e } \\
\text { filtração HEPA de ar emergente) }\end{array}$ & - & $\mathrm{R}$ & $\mathrm{O}$ & - \\
\hline $\begin{array}{l}\text { Trabalho em cabine de segurança biológica tipo III (com 100\% exaustão e } \\
\text { filtração HEPA de ar emergente e área de trabalho fechada acessível apenas por } \\
\text { luvas) (com filtração HEPA de ar emergente) }\end{array}$ & - & - & $\mathrm{R}$ & $\mathrm{O}$ \\
\hline Agitações feitas apenas no interior de cabine de segurança CSB & $\mathrm{R}$ & $\mathrm{R}$ & $\mathrm{O}$ & $\mathrm{O}$ \\
\hline Homogeneizações feitas apenas em cabine CSB & $\mathrm{R}$ & $\mathrm{R}$ & $\mathrm{O}$ & $\mathrm{O}$ \\
\hline Sonicagens feitas apenas no interior de cabine CSB & $\mathrm{R}$ & $\mathrm{R}$ & $\mathrm{O}$ & $\mathrm{O}$ \\
\hline Centrifugação em suportes tampados & $\mathrm{R}$ & $\mathrm{R}$ & $\mathrm{O}$ & $\mathrm{O}$ \\
\hline "Carregar" suporte de centrífuga no interior de cabine CSB & $\mathrm{R}$ & $\mathrm{R}$ & $\mathrm{O}$ & $\mathrm{O}$ \\
\hline Retirar tubos de suporte de centrífuga apenas no interior de CSB & $\mathrm{R}$ & $\mathrm{R}$ & $\mathrm{O}$ & $\mathrm{O}$ \\
\hline Autoclave & $\mathrm{R}$ & $\mathrm{O}$ & $\mathrm{O}$ & $\mathrm{O}$ \\
\hline
\end{tabular}

Fonte: Correia (2019). 
Lavatório para lavagem das mãos, lava-olhos, chuveiros de emergência também são equipamentos eficientes, desde que sejam posicionados e usados corretamente, devendo estar presentes nas áreas em contenção e adjacentes à área do laboratório. Deve haver pelo menos um lavatório para lavagem das mãos, com acionamento automático próximo à porta de saída de cada laboratório a partir de NB-2.

A partir do nível de segurança NB-3 os laboratórios devem possuir sistema de emergência constituído de grupo motor-gerador e chave automática de transferência, para alimentar os circuitos da iluminação de emergência, dos alarmes de incêndio e de segurança predial, dos demais equipamentos essenciais, tais como: cabine de segurança biológica (CSB), freezers, refrigeradores, incubadoras, e condicionamento de ar em ambientes que necessitam de temperatura e fluxo unidirecional constante do ar. Devem ser instaladas coifas sobre equipamentos que realizam procedimentos que possam produzir aerossóis. Essas coifas devem estar interligadas ao sistema de tratamento de ar com filtragem absoluta (HEPA).

\section{Aspectos para projetos de laboratório para pesquisa em saúde}

Os laboratórios devem ser projetados de forma a que atendam às normas, com a especificação de materiais de construção adequados, e devem possuir dispositivos que assegurem adequadas condições ambientais para a realização das atividades com conforto, segurança e a proteção da saúde ocupacional, inclusive acústica, temperatura, iluminação, ventilação e umidade relativa do ar.

Por exemplo, pelas normas trabalhistas em vigor, as áreas de circulação e os espaços em torno de máquinas e equipamentos devem ser dimensionados de forma que o material e os trabalhadores possam movimentar-se com segurança. Já nos trabalhos onde o operador trabalha sentado devem ser fornecidos assentos adequados e ergonômicos (BRASIL, 2019).

Há situações em que são necessárias salas exclusivas para proteção de instrumentos e equipamentos contra interferências elétricas, vibrações, ruídos internos e externos, contato excessivo com umidade, circulação de pessoas e outros fatores externos (AGÊNCIA..., 2014).

No caso de ambientes que precisam estar isolados de riscos potenciais vindos do exterior, estes devem ter pressão atmosférica positiva. Já no caso de ambientes onde se utilizam patógenos, a pressão atmosférica deve ser negativa. Em ambos não devem ocorrer trocas de ar por infiltração. Essa garantia se dá basicamente pelos sistemas de ventilação mecânica (insuflamento e exaustão), mas como indica Barbosa (2017), não deve ser mantida uma alta turbulência do ar nos ambientes laboratoriais, por questão de biossegurança.

Os laboratórios de pesquisa são áreas críticas, nas quais as atividades não podem ser interrompidas abruptamente em função dos riscos envolvidos e, como tal, devem ser controladas dentro de critérios prédeterminados de segurança. $\mathrm{O}$ fornecimento de energia elétrica, a iluminação e o sistema de tratamento de ar devem ser apropriados e contínuos de modo a não afetar direta ou indiretamente as atividades, o conforto e a segurança.

Outros requisitos físicos devem ser incorporados aos espaços de laboratórios, normalmente agrupados conforme suas funções. É preciso haver controle de acessos, circulação independente, área de higiene e descontaminação (de pessoas, insumos, resíduos e equipamentos), área de utilidades e de equipamentos, sistemas de emergência e perímetro de contenção definido. Também é necessário evitar a ocorrência de contaminação cruzada (contaminação de um material por outro) e a entrada de insetos e outros vetores. Tudo sinalizado conforme as normas correspondentes a cada tipo de atividade e riscos envolvidos (TEIXEIRA; VALLE, 1996; COSTA, 2011; AGÊNCIA..., 2014). Dessa forma, a concepção de ambientes laboratoriais deve ter, por princípio, a facilidade de limpeza, descontaminação e manutenção.

Equipamentos laboratoriais, como freezers, centrífugas, coifas, entre outros, são fontes importantes de ruído interno. Gaiolas ventiladas para os animais de laboratório também geram ruído. O projeto deve dar resposta à questão dos ruídos gerados no interior dos laboratórios, sejam aéreos ou por impacto (vibração, atrito, etc.). Quanto maior o tempo de permanência no laboratório, maior é a exposição ao ruído, levando a um limite máximo mais baixo.

Para as áreas laboratoriais, os projetos de arquitetura devem considerar as áreas técnicas nos pavimentos para instalação dos quadros elétricos e shafts nas prumadas interligando os pavimentos.

Para trabalhar em laboratório com animais, quer seja em biotério de criação ou de experimentação, é necessário atender a requisitos adicionais a serem adotados segundo a espécie animal, o risco potencial do agente, as atividades do biotério e as condicionantes locais.

Adicionalmente, outros fatores se somam aos citados na classificação dos níveis de risco à saúde. A OMS

222 Correia, M. C.; Leal, B. M. F.; Bastos, L. E. G. 
(ORGANIZAÇÃO..., 2004), Costa (2011) e Pessoa e Lapa (2003) afirmam que profissionais que atuam em laboratórios de pesquisa, ensino e diagnóstico de saúde constituem o grupo de maior risco dentre os profissionais que trabalham na área da saúde. Os laboratórios de ensino e pesquisa são os considerados de maior risco à saúde devido à alta rotatividade de pessoas, aos insumos e à diversificação de equipamentos utilizados.

Com relação à biossegurança, o projeto de arquitetura precisa atender aos seguintes aspectos:

(a) possibilitar controle de acesso, inclusive estabelecendo circulação linear e pontos com boa visibilidade para os sistemas CFTV;

(b) perímetro de contenção definido;

(c) o leiaute laboratorial precisa facilitar a realização dos experimentos e a circulação;

(d) a higiene e a descontaminação precisam ser garantidas e o processo ser facilitado, o que inclui sala de lavagem adequada aos equipamentos;

(e) mobiliário e todas as superfícies precisam ser adequados às atividades laboratoriais;

(f) tratamento adequado de resíduos é essencial à segurança e inclui higienização, neutralização, armazenamento temporário e transporte;

(g) utilidades e equipamentos são essenciais ao funcionamento do laboratório;

(h) sistemas de ventilação e refrigeração são essenciais para estabelecer a contenção, o conforto aos usuários e a qualidade do ar interior (QAI); e

(i) sistemas de emergência e acidentes são essenciais para manter os sistemas de ventilação e refrigeração, os controles de acesso e equipamentos laboratoriais, inclusive estantes e gaiolas ventiladas funcionando.

O projeto ainda deve atender a normas gerais trabalhistas, de arquitetura e a algumas específicas como de acústica, como:

(a) normas regulamentadoras trabalhistas do Ministério do Trabalho em vigor (BRASIL, 2019);

(b) normas de arquitetura como a norma de acessibilidade a edificações, mobiliário, espaços e equipamentos urbanos, NBR 9050 (ABNT, 2015) e versões mais atualizadas; e

(c) norma de acústica, como NBR ISO 16283-1 (ABNT, 2018), NBR 10052 (ABNT, 2020) e versões mais atualizadas.

Dessa forma, são esses os aspectos arquitetônicos considerados mais relevantes nas análises tratadas no estudo de caso deste trabalho.

\section{Sustentabilidade e métodos de avaliação da qualidade ambiental de edificações}

\section{Métodos de referência internacional na avaliação da qualidade ambiental de edificações}

As discussões globais sobre os conceitos de sustentabilidade datam de 1987, tendo como marco o relatório das Nações Unidas conhecido como Our Common Future (UNITED..., 1987). A Constituição incorporou alguns desses conceitos (BRASIL, 1988). Nos últimos dez anos o Brasil retomou a edição de normas de obrigatoriedade para as licitações públicas (BRASIL, 2010). Considerando a importância da gestão eficiente e econômica dos recursos públicos para a sociedade é indiscutível a importância da utilização de ferramentas de avaliação para o processo de projeto de edificações, principalmente as gratuitas.

Fundamentando-se na literatura, a partir da década de 80 as primeiras certificações energético-ambientais: a francesa HQE, a inglesa BREEAM, a canadense GBTool e o SBTool (INTERNATIONAL..., 2016), criado por cooperação internacional. O método norte-americano LEED surge em 2000 (CORREIA; SALGADO, 2016).

O método HQE foi adaptado para o Brasil em 2007 sob a denominação Avaliação de Qualidade Ambiental (AQUA), com o compromisso de seguir o mesmo referencial que a matriz francesa, dando validade internacional as suas certificações, e desde 2013 passou a ser denominado AQUA-HQE (FUNDAÇÃO VANZOLINI, 2019). 
A Associação Francesa HQE, em maio de 2015, lançou uma revisão significativa do sistema de classificação ambiental HQE (HAUTE..., 2015; CORREIA; SALGADO, 2016). No Brasil o método denominado AQUA-HQE permanece seguindo a versão-base original francesa de 2007.

Segundo Salgado (2017) a metodologia AQUA-HQE certificou mais de 235 edificações e o método LEED alcançou a marca de 354 certificações.

Uma certificação energético-ambiental pode onerar o custo do processo de realização da edificação, como exemplificado nas Tabelas 1 a 3. Já o ASUS (SOUZA, 2008), adaptação acadêmica brasileira do SBTool para edificações comerciais, assim como o próprio SBTool, não apresentam nenhum ônus.

Exemplificando o cálculo dos ônus referentes à certificação LEED (Tabela 1), para os dois projetos, "A" e "B", selecionou-se as opções: localização "global", "não membro", auditoria de certificação combinada (combined review), modelo "projeto e construção" (BD + C do inglês Building Design + Construction) que inclui custos de projeto e de construção. Nesses valores já estão incluídos um consultor LEED experiente dedicado e o acesso à plataforma online $\mathrm{Arc}^{2}$. Ambos os projetos "A" e "B" se enquadram na faixa de área bruta do projeto até $23.225,57 \mathrm{~m}^{23}$, excluindo estacionamento.

A simulação de custo aproximado da certificação AQUA pode ser realizada pelo sítio, em "calculadora"" Foram usados os dados das mesmas edificações, explicitados na Tabela 2.

Para a área menor, o valor da proposta comercial diferiu pouco do informado pela "calculadora". O valor estimado das certificações AQUA inclui as três fases - pré-projeto (programa), projeto e execução, assim como as análises do processo, auditorias, avaliação das fases e o uso da marca (FUNDAÇÃO..., 2019). Porém, diferente da certificação anterior, não inclui a consultoria. Pelo exame das Tabelas 1 e 2 verifica-se não ser possível estabelecer uma proporcionalidade na relação custos das duas certificações $\mathrm{R} \$ / \mathrm{m}^{2}$ para uma edificação.

$\mathrm{Na}$ formação desses custos unitários básicos, por suas individualidades, não são considerados itens importantes, como fundações, paredes-diafragma, tirantes, rebaixamento de lençol freático; elevador(es); equipamentos e instalações, bombas de recalque, incineração, ar-condicionado, ventilação e exaustão, impostos, taxas e emolumentos cartoriais, projetos: projetos arquitetônicos, projeto estrutural, projeto de instalação, projetos especiais; remuneração do construtor. Como forma de amenizar essas omissões foi considerado o custo para edificação de 16 pavimentos.

A Tabela 3 apresenta análises a partir do custo estimado para construção das edificações "A" e "B". Os custos estimados das obras para as edificações "A" e "B" se basearam no CUB maio 2019 (SINDICATO..., 2019).

Tabela 1 - Custos para certificação LEED estimada no Brasil

\begin{tabular}{|c|c|c|}
\hline \multicolumn{3}{|c|}{ Simulações certificação LEED } \\
\hline & Edificação A & Edificação B \\
\hline Área total da edificação $\left(\mathrm{m}^{2}\right)$ & $6.000 \mathrm{~m}^{2}$ & $23.000 \mathrm{~m}^{2}$ \\
\hline Área equivalente em pés quadrados (sft) & $64.584 \mathrm{sft}$ & $247.572,00 \mathrm{sft}$ \\
\hline \multirow{2}{*}{ Custo taxa fixa de registro (reais e dólares americanos) } & \multicolumn{2}{|c|}{$\mathrm{R} \$ 6.090,00$} \\
\hline & \multicolumn{2}{|c|}{$(\$ 1.500)$} \\
\hline \multirow{2}{*}{ Auditoria documental (pré-certificação) } & \multicolumn{2}{|c|}{$\mathrm{R} \$ 20.300,00$} \\
\hline & \multicolumn{2}{|c|}{$(\$ 5.000)$} \\
\hline \multirow{2}{*}{$\begin{array}{l}\text { Certificação BD + C_até } 23.000 \mathrm{~m}^{2} \text { (custo mínimo \$ } \\
3.420=\mathrm{R} \$ 13.885,00 \text { em } 5 \text { out. } 2019 \text { ) }\end{array}$} & $\mathrm{R} \$ 17.830,35$ & $\mathrm{R} \$ 68.350,00$ \\
\hline & Taxa por $\mathrm{sft}=\$ 0,068$ & Taxa por $\mathrm{sft}=\$ 0,068$ \\
\hline Consultoria & incluído & incluído \\
\hline Totais & $\mathrm{R} \$ 44.220,35$ & $\mathrm{R} \$ 94.740,00$ \\
\hline Relação custos certificação/m² & $7,37 / \mathrm{m}^{2}$ & $4,12 / \mathrm{m}^{2}$ \\
\hline
\end{tabular}

Fonte: Correia (2019).

${ }^{2}$ Arc. Disponível em: https: //arcskoru.com/. Acesso em: ago. 2019.

${ }^{3}$ Conversão de medidas para 250.000 pés quadrados informados no sítio: https://new.usgbc.org/cert-guide/fees. Acesso em set. 2019.

${ }^{4}$ Fundação Vanzolini. Calculadora. Disponível em: https://vanzolini.org.br/aqua/calculadora/. Acesso em set. 2019. 
Tabela 2 - Custos estimativos para certificação AQUA no Brasil

\begin{tabular}{l|c|c}
\hline \multicolumn{3}{c}{ Simulações AQUA } \\
\hline Área total da edificação $\left(\mathrm{m}^{2}\right)$ & Edificação A & Edificação B \\
\hline Custo certificação conforme proposta real apresentada & $6.000 \mathrm{~m}^{2}$ & $23.000 \mathrm{~m}^{2}$ \\
\hline Relação custo "proposta"/m" & $\begin{array}{c}\mathrm{R} \$ 42.749,00 \\
\text { (data abr } 2019)\end{array}$ & $\begin{array}{c}\mathrm{R} \$ 96.000,00 \\
(\text { data dez 2018) }\end{array}$ \\
\hline Custo certificação conforme "calculadora” & $7,125 / \mathrm{m}^{2}$ & $4,174 / \mathrm{m}^{2}$ \\
\hline Relação custo "calculadora"/m² & $\mathrm{R} \$ 42.779,00$ & $\mathrm{R} \$ 90.379,00$ \\
\hline Consultoria & $7,129 / \mathrm{m}^{2}$ & $3,929 / \mathrm{m}^{2}$ \\
\hline Totais & Opcional, à parte & Opcional, à parte \\
\hline
\end{tabular}

Fonte: Correia (2019).

Tabela 3 - Análises percentuais sobre custo estimado das obras

\begin{tabular}{l|c|c}
\hline \multicolumn{3}{c}{ Análises custo e proporcionalidade das certificações } \\
\hline \multicolumn{1}{c}{ Edificação A } & Edificação B \\
\hline Área total da edificação $\left(\mathrm{m}^{2}\right)$ & $6.000 \mathrm{~m}^{2}$ & $23.000 \mathrm{~m}^{2}$ \\
\hline $\begin{array}{l}\text { Custo estimado da obra } \\
\text { (Sinduscon-MG CUB CSL-16) }\end{array}$ & $\begin{array}{c}\mathrm{R} \$ 12.806 .460,00 \\
\text { (data maio 2019) }\end{array}$ & $\begin{array}{c}\mathrm{R} \$ 49.091 .430,00 \\
\text { (data maio 2019) }\end{array}$ \\
\hline Custo certificação LEED* & $\mathrm{R} \$ 44.220,35$ & $\mathrm{R} \$ 94.740,00$ \\
\hline Custo certificação AQUA conforme "calculadora"** & $\mathrm{R} \$ 42.779,00$ & $\mathrm{R} \$ 90.379,00$ \\
\hline Relação percentual certif. LEED x custo da obra & $0,35 \%$ & $0,19 \%$ \\
\hline Relação percentual certif. AQUA x custo da obra & $0,33 \%{ }^{2}$ & $0,18 \%$ \\
\hline
\end{tabular}

Fonte: Correia (2019).

Nota: *inclui custo consultoria.

**não inclui custo consultoria.

Como mencionado na Introdução, legalmente não é exigido para a realização de uma obra um processo de certificação comercial. No entanto, quando do exame de avaliação de um projeto para um prédio público pelas autoridades competentes, caso o projeto já tenha atendido a algum procedimento relativo à qualidade energético-ambiental, esse fato poderia contribuir para a qualidade da futura construção. Assim, com o intuito de mostrar o potencial de uma ferramenta gratuita de avaliação, com o enfoque na sustentabilidade, o presente artigo aborda o método $S B$-Method.

\section{Método “edificação sustentável” (SB-Method) adotado na avaliação de sustentabilidade em estudo de caso de laboratório}

Esse método de análise ainda é pouco conhecido no Brasil. O Sustainable Building Method - SB-Method utiliza a ferramenta SBTool, desenvolvida em 1996 pelo consórcio de países constituintes dos organismos Sustainable Building Challenge (SBC) e da International Initiative for a Sustainable Built Environment (iiSBE). Um conjunto de organizações internacionais não lucrativas, cujo objetivo geral é facilitar e promover a adoção de políticas, métodos e ferramentas para acelerar o movimento sustentável global para o meio ambiente construído, sediado em Ottawa, no Canadá (LARSSON, 2015; SOUZA, 2008). O método permite uma avaliação com grande acessibilidade e vantagens perante outras certificações, uma vez que é gratuito, flexível e adaptável às especificidades locais.

Assim, o SBMethod deu origem a diferentes certificações como o SBTool ${ }^{\mathrm{PT}}$ (Portugal), desenvolvido através de pesquisas acadêmicas da Universidade do Minho, coordenadas pelo professor Luis Bragança, o Protocollo ITACA (Itália), ao SBTool CZ (República Checa) e o ASUS (Brasil), desenvolvido através de pesquisas acadêmicas da UFES, coordenadas pela professora Cristina Engels. O método também propiciou o surgimento da Rede Comunidades Urbanas Energeticamente Eficientes (URBENERE) (Brasil e Portugal), resultado de parceria entre UFES, UMinho e iiSBE (LARSSON, 2015).

Vale ressaltar que essa ferramenta genérica em princípio não promove a certificação. Entretanto, caso haja interesse local em uma parceria e, uma vez que unidades locais iiSBE sejam instaladas, estas podem determinar se haverá ou não uma certificação, como ocorreu na Itália com o Protocollo ITACA. 
A ferramenta de análise de desempenho é composta de duas planilhas eletrônicas interligadas (Excel) planilha "A" e "B" - contendo os requisitos, agrupados por categorias, estabelecendo indicadores e pesos, em um escopo genérico. Ela aceita até três perfis de ocupação para uma edificação: comercial, residencial, além de estacionamento para veículos e usos mistos.

As planilhas contêm alguns valores já definidos, além de outra parte ajustável de acordo com as condições e especificidades do local, que devem ser definidas a priori. Durante processo de análise, os avaliadores devem preencher as células das planilhas com valores numéricos que considerem corretos para cada requisito e o resultado final da avaliação é processado automaticamente pela ferramenta, que considera as características do local: latitude, longitude, as soluções de referências - benchmarks, emissões de gases, entre outros (LARSSON, 2012). Ou seja, utiliza-se a melhor prática construtiva local como referência zero da classificação. Assim, a pontuação final varia de -1 (caso com pior condição em relação ao benchmark) a +5 (melhor prática). Cria-se assim a possibilidade de um círculo virtuoso de melhoria contínua. A ferramenta é flexível e os requisitos a serem analisados podem ser selecionados, segundo cada critério.

A Figura 1 demonstra a flexibilidade na seleção do escopo, sob três opções: a imagem à esquerda contém todos os requisitos do escopo da sustentabilidade; na imagem central a seleção abrange apenas o escopo mínimo, correspondendo aos critérios essenciais de avaliação; à direita foram acrescidos à seleção um grupo maior de critérios além dos mínimos, variável entre os dois anteriores. Dessa forma uma edificação pode ser avaliada conforme a abrangência do escopo considerado.

As planilhas contêm uma definição de pesos default, baseados em dados canadenses (Quadro 5).

Os pesos possuem influência na pontuação final, e são considerados segundo aspectos sustentáveis mais relevantes para aquele local. Os pesos por "default" baseados em dados canadenses que foram considerados inadequados ao contexto local do Brasil foram desativados, de forma a não interferir na avaliação. Nenhum critério foi acrescentado para essa investigação.

Parte das informações deve ser fornecida pelos projetistas, que preenchem dados e informações específicas de projeto. Ou também pela própria coordenação do projeto, por consultores locais a serem contratados ou ainda pela organização iiSBE regional, caso exista. Se não houver informação para um critério ou se este for considerado sem importância para a análise do edifício, o critério pode ser desativado e não irá interferir na avaliação final (LARSSON, 2012).

Na ausência de consultores SBTool e de uma organização iiSBE regional no Brasil, não houve nenhuma adaptação de maior porte para essa investigação.

O Quadro 6 indica as categorias do SBTool e a quantidade de indicadores, conforme o escopo da avaliação e as fases do ciclo de vida: pré-projeto (programa-estudo preliminar e anteprojeto), projeto, construção e operação.

Essas oito categorias estabelecidas para a sustentabilidade indicadas no Quadro 6 são consideradas nas análises realizadas no estudo de caso deste trabalho. O escopo mínimo contém 8 indicadores de pré-projeto e 14 de projeto, totalizando 22 indicadores, destacados no Quadro 6.

\section{Figura 1 - Escopo SBTool}
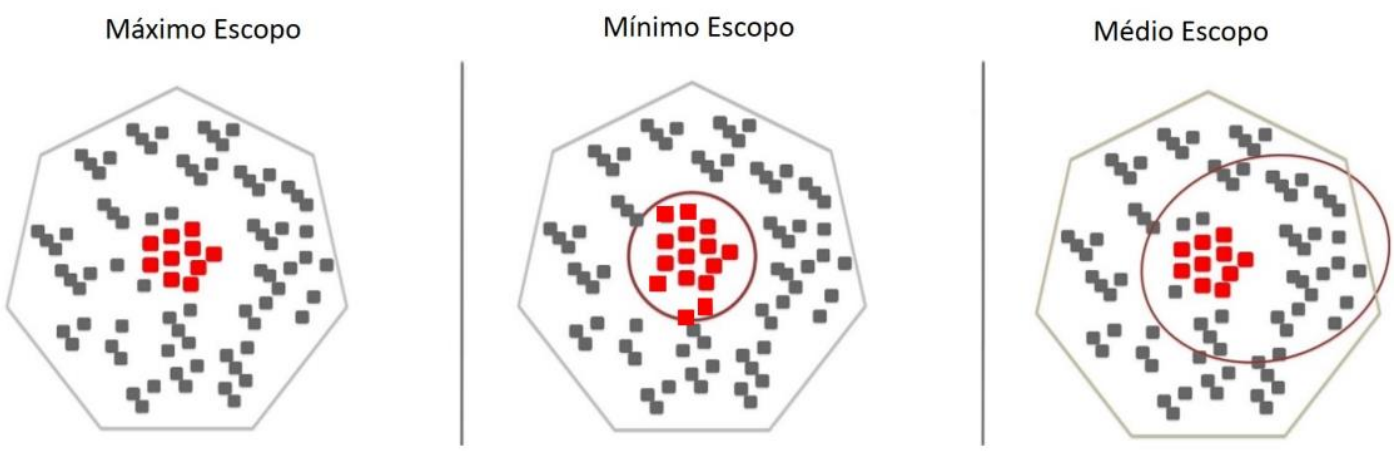

Legenda: Critério Obrigatório a Critério Opcional Eletivo

Fonte: Larsson (2015). 
Quadro 5 - Base para o critério de pesos do SBTool

\begin{tabular}{|c|c|c|c|c|}
\hline Parte ajustável & \multicolumn{4}{|c|}{ Valores previamente definidos } \\
\hline $\begin{array}{c}\text { Efeitos potenciais } \\
\text { de cargas e } \\
\text { qualidades }\end{array}$ & $\begin{array}{l}\text { Extensão do } \\
\text { efeito potencial } \\
\text { (1 a } 5 \text { pontos })\end{array}$ & $\begin{array}{c}\text { Duração do efeito } \\
\text { potencial (1 a } 5 \\
\text { pontos) }\end{array}$ & $\begin{array}{l}\text { Intensidade do } \\
\text { efeito potencial } \\
\text { (1 a } 5 \text { pontos })\end{array}$ & $\begin{array}{c}\text { Sistema primário } \\
\text { diretamente afetado } \\
\text { (1 a } 5 \text { pontos })\end{array}$ \\
\hline 1) Muito menos & 1) Edifício & 1) 1 a 3 anos & 1) Menor & 1) Serviços \\
\hline 2) Menos & 2) Sítio/projeto & 2) 3 a 10 anos & 2) Moderado & 1) Custo e economia \\
\hline 3) $\mathrm{OK}$ & 3) Vizinhança & 3) 10 a 30 anos & 3) Maior & $\begin{array}{l}\text { 2) Conforto humano } \\
\text { e bem-estar }\end{array}$ \\
\hline 4) Mais & $\begin{array}{l}\text { 4) } \\
\text { Urbano/regional }\end{array}$ & 4) 30 a 75 anos & & $\begin{array}{l}\text { 2) Recursos não } \\
\text { energéticos }\end{array}$ \\
\hline \multirow[t]{6}{*}{ 5) Muito mais } & 5) Global & 5) $>75$ anos & & $\begin{array}{l}\text { 3) Recursos } \\
\text { energéticos }\end{array}$ \\
\hline & & & & 3) Recursos aquíferos \\
\hline & & & & 4) Saúde humana \\
\hline & & & & $\begin{array}{l}\text { 4) Sistemas } \\
\text { ecológicos }\end{array}$ \\
\hline & & & & 5) Segurança de vida \\
\hline & & & & 5) Sistema climático \\
\hline
\end{tabular}

Fonte: Larsson e Bragança (2016) e Correia e Leal (2016).

Quadro 6 - Categorias e indicadores do SBTool

\begin{tabular}{|c|c|c|c|c|c|c|}
\hline \multirow{2}{*}{\multicolumn{2}{|c|}{ Categorias }} & \multirow{3}{*}{$\begin{array}{c}\text { Escopo } \\
\text { Max }\end{array}$} & \multicolumn{4}{|c|}{ Quantidade de indicadores por fase do ciclo de vida } \\
\hline & & & \multirow{2}{*}{$\frac{\text { Pré-projeto }}{35}$} & \multirow[t]{2}{*}{ Projeto } & \multirow[t]{2}{*}{ Construção } & Operação \\
\hline \multirow{3}{*}{1} & \multirow{3}{*}{$\begin{array}{l}\text { Localização, } \\
\text { características locais e } \\
\text { serviços disponíveis }\end{array}$} & & & & & \\
\hline & & Med & 20 & & & \\
\hline & & Min & 8 & & & \\
\hline \multirow{3}{*}{2} & \multirow{3}{*}{$\begin{array}{l}\text { Recuperação do solo, } \\
\text { desenho urbano e } \\
\text { infraestrutura }\end{array}$} & Max & & 22 & 0 & 21 \\
\hline & & Med & & 12 & 0 & 11 \\
\hline & & Min & & 2 & 0 & 2 \\
\hline \multirow{3}{*}{3} & \multirow{3}{*}{$\begin{array}{l}\text { Consumo de energia e } \\
\text { de recursos }\end{array}$} & Max & & 10 & 6 & 10 \\
\hline & & Med & & 8 & 4 & 7 \\
\hline & & Min & & 4 & 2 & 3 \\
\hline \multirow{3}{*}{4} & \multirow{3}{*}{ Cargas ambientais } & Max & & 19 & 7 & 18 \\
\hline & & Med & & 6 & 1 & 6 \\
\hline & & Min & & 2 & 0 & 2 \\
\hline \multirow{3}{*}{5} & \multirow{3}{*}{$\begin{array}{l}\text { Qualidade ambiental } \\
\text { interna }\end{array}$} & Max & & 18 & 0 & 19 \\
\hline & & Mid & & 10 & 0 & 10 \\
\hline & & Min & & 2 & 0 & 2 \\
\hline \multirow{3}{*}{6} & \multirow{3}{*}{ Qualidade do serviço } & Max & & 20 & 9 & 25 \\
\hline & & Med & & 10 & 4 & 13 \\
\hline & & Min & & 2 & 1 & 2 \\
\hline \multirow{3}{*}{7} & \multirow{3}{*}{$\begin{array}{l}\text { Percepção e aspectos } \\
\text { socioculturais }\end{array}$} & Max & & 10 & 2 & 10 \\
\hline & & Med & & 5 & 1 & 5 \\
\hline & & Min & & 1 & 0 & 1 \\
\hline \multirow{3}{*}{8} & \multirow{3}{*}{$\begin{array}{l}\text { Custo e aspectos } \\
\text { econômicos }\end{array}$} & Max & & 4 & 1 & 4 \\
\hline & & Med & & 3 & 1 & 3 \\
\hline & & Min & & 1 & 0 & 1 \\
\hline \multirow{3}{*}{\multicolumn{2}{|c|}{ Total }} & Max & 35 & 103 & 25 & 107 \\
\hline & & Med & 20 & 54 & 11 & 55 \\
\hline & & Min & 8 & 14 & 3 & 13 \\
\hline
\end{tabular}

Fonte: Larsson (2012). 


\section{Estudo de caso: projeto de instalações laboratoriais da nova sede da Fiocruz em Minas Gerais}

A Fiocruz obteve a certificação de sustentabilidade AQUA-HQE para o projeto de sua nova sede regional para o Centro de Pesquisa René Rachou, cujas instalações irão abrigar laboratórios, áreas de apoio e administrativas, em dois edifícios, com alturas distintas (Figura 2). Em 2016 houve uma certificação no âmbito de pré-projeto (programa de edificação não residencial - versão março 2014), e em 2017 a certificação do projeto, na mesma versão, para os temas de energia e economias, meio ambiente, saúde e segurança, e conforto (FUNDAÇÃO..., 2019). Foi esse o projeto escolhido para testar a ferramenta gratuita e avaliar seus resultados.

O programa complexo dessa instalação inclui laboratórios de pesquisa e suas áreas de apoio, além do alojamento de animais e áreas administrativas. Assim, serão 11.129,12 $\mathrm{m}^{2}$ de laboratórios (23\%), 18.048,50 $\mathrm{m}^{2}$ de áreas administrativas (37\%), 13.171,04 $\mathrm{m}^{2}$ de áreas de apoio técnico $(27 \%), 4.834,48 \mathrm{~m}^{2}$ de parque de estacionamento subterrâneo (10\%) e $811,21 \mathrm{~m}^{2}$ de jardins (1\%), totalizando 45.094,62 $\mathrm{m}^{2}$ nos seus oito níveis com um nível de piso de estacionamento semissubterrâneo. A proposta inclui o fornecimento de transporte institucional para o deslocamento de seus funcionários, como já existe nas outras unidades.

Para viabilizar esse empreendimento foi realizado um estudo sobre as águas superficiais e propostos dois projetos:

(a) drenagem de águas pluviais; e

(b) uma rede de esgoto, pois havia lançamentos no curso de água (objeto de canalização parcial).

No térreo dessa edificação estão sendo propostos: auditório, biblioteca e sala de exposição de um museu interativo com o intuito de disseminar ciência para a população da cidade.

A edificação viabilizará um fluxo regular de pessoas à localidade, o que poderá favorecer maior visibilidade, segurança e redes de infraestrutura para a vizinhança. Com o aumento da circulação de pessoas deve aumentar a oferta e a circulação de transporte público. As pesquisas que serão realizadas trarão benefícios à sociedade como um todo.

Esse conjunto de fatores mostra os efeitos positivos dessa iniciativa no âmbito local e até regional.

Figura 2 - Centro de Pesquisa René Rachou, futura nova sede da Fiocruz Minas

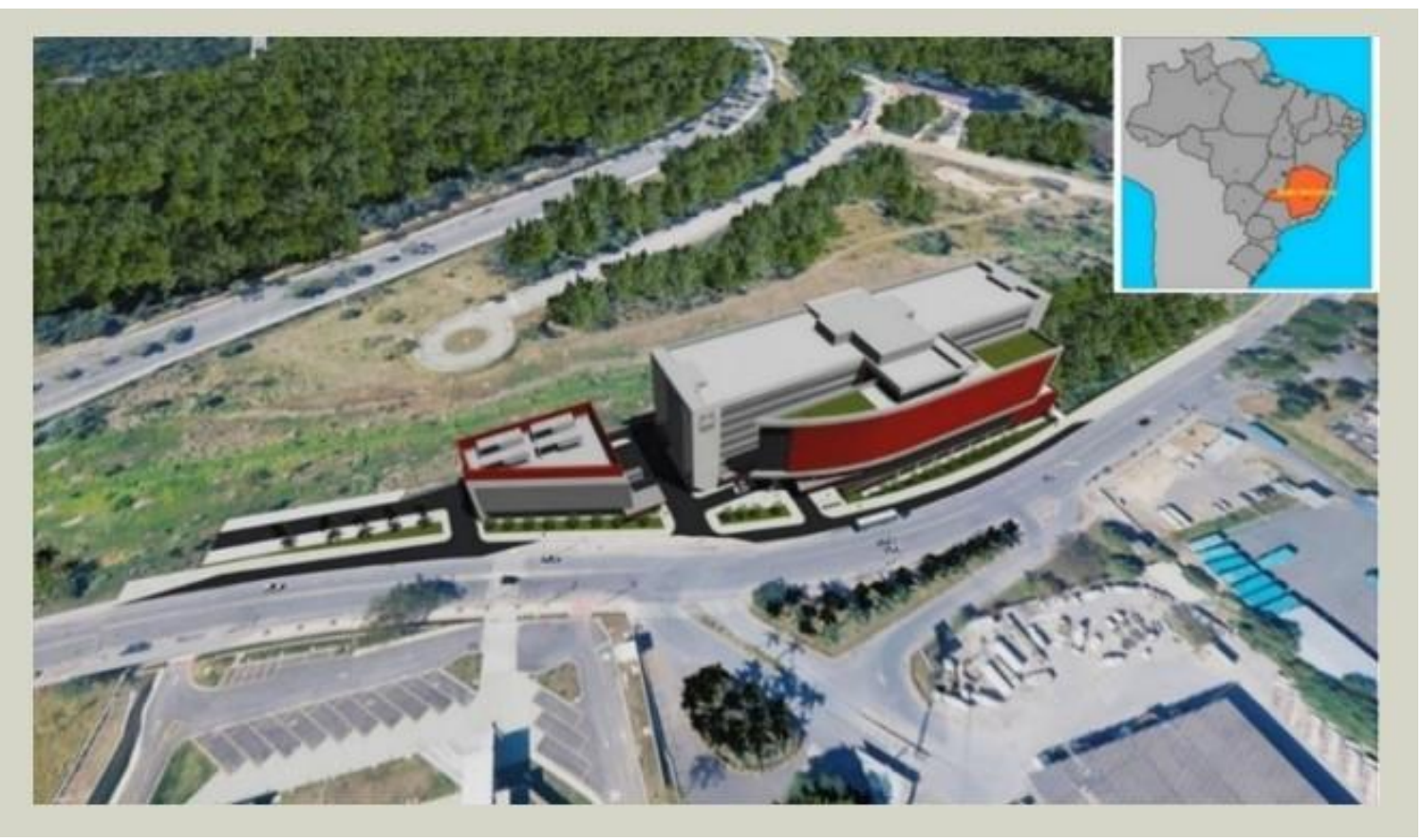

Fonte: adaptado de Fiocruz Minas (FUNDAÇÃO..., 2019). 
A Figura 3 mostra a planta baixa do terceiro pavimento (áreas destinadas aos laboratórios identificados em rosa e as áreas administrativas em amarelo) e a Figura 4 apresenta uma ampliação de área de laboratório indicada por um retângulo vermelho no terceiro pavimento.

A área administrativa comporta 78,95 $\mathrm{m}^{2}$ de escritórios, 186,21 $\mathrm{m}^{2}$ de áreas de apoio (banheiros normais e acessíveis masculino e feminino, almoxarifado, depósito de material de limpeza - DML geral, DML dos laboratórios, depósito temporário de resíduos, arquivo morto) e 184,69 $\mathrm{m}^{2}$ de áreas colaborativas (salas de apoio e café, sala de convívio, salas de reunião, salas de formação de alunos). As áreas de circulação horizontal, incluindo a circulação laboratorial, totalizam $1.062,30 \mathrm{~m}^{2}$.

Figura 3 - Planta baixa do terceiro pavimento do edifício principal - nova sede da Fiocruz em Belo Horizonte, Brasil

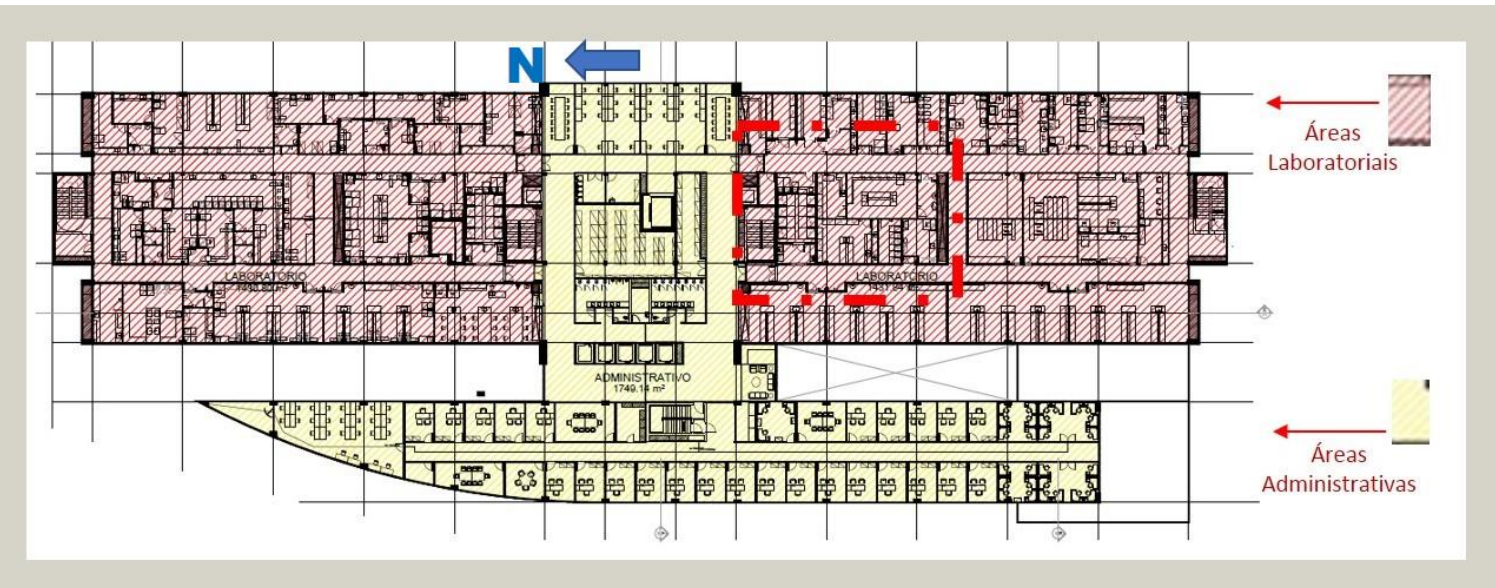

Fonte: adaptado de Fiocruz Minas (FUNDAÇÃO..., 2019).

Figura 4 - Detalhe do laboratório (moluscos) no terceiro pavimento

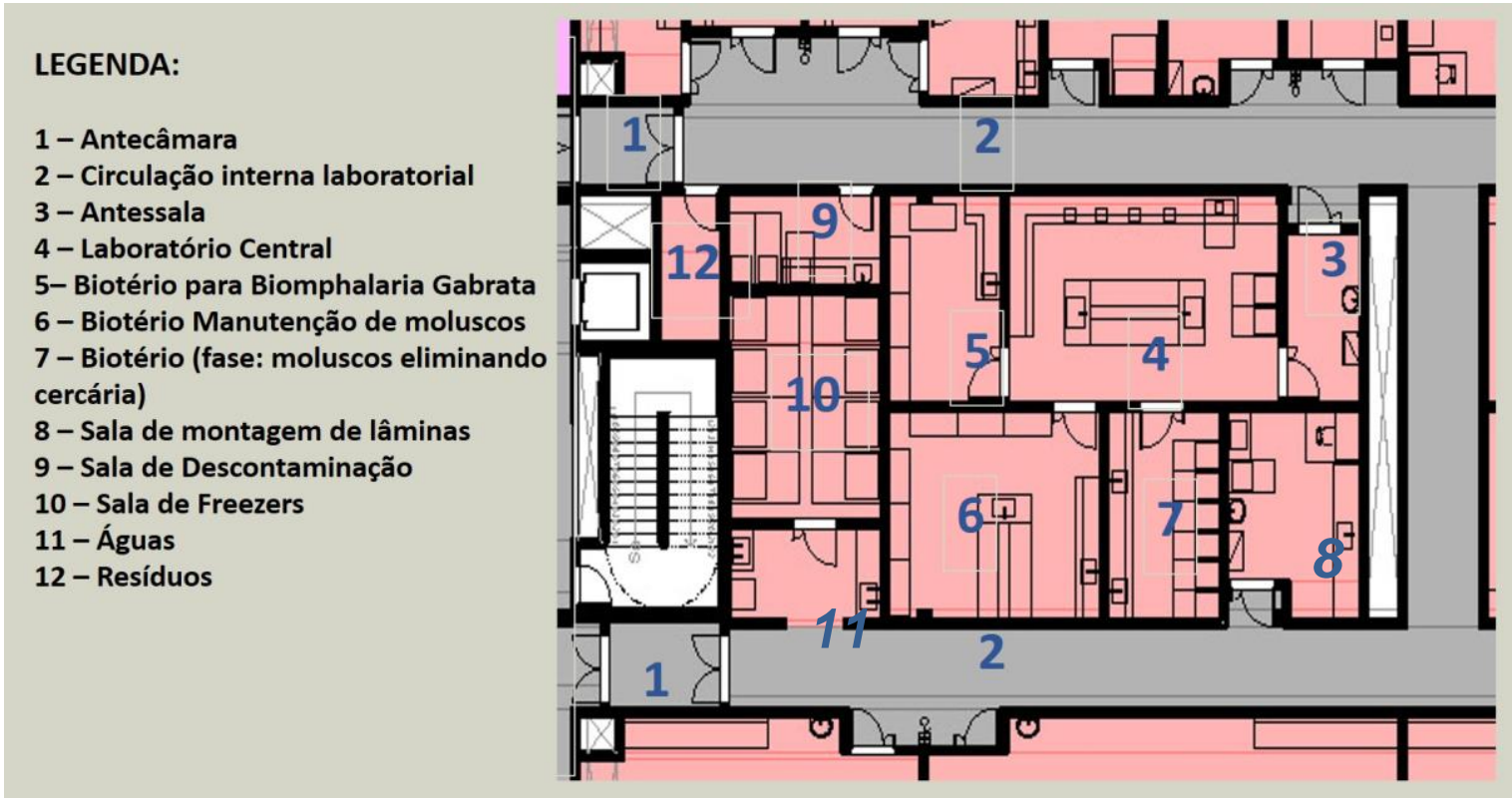

Fonte: adaptado de Fiocruz Minas (2019). 
A Figura 4 mostra um detalhe de um biotério que utiliza moluscos como biomodelos ${ }^{5}$, onde são indicados alguns compartimentos para facilitar a compreensão da proposta. Como pode ser visto, as antecâmaras e a circulação interna dão acesso a vários outros laboratórios. Um laboratório NB2 serve de acesso e age como barreira adicional para um laboratório NB3 e assim por diante. O acesso a cada um precisa ser controlado.

A Figura 5 mostra detalhe de outro laboratório da mesma edificação, com aplicação de barreiras arquitetônicas como os vestiários de barreira, a quarentena para os animais, espaço adequado para higienização e descontaminação dos materiais e equipamentos laboratoriais, circulação separada entre interna limpa, interna potencialmente suja e interna suja, através de barreiras: airlock, antecâmaras e próprias salas de trabalho como a de autoclaves e a quarentena.

Interessante observar os percursos de caráter linear que são possíveis a partir das entradas. Pode-se analisar como foram resolvidos arquitetonicamente a barreira de acesso e os perímetros de contenção sequenciados. A proposta de arquitetura ainda permite o controle de acesso, a separação dos fluxos e as demais condições projetuais.

\section{Análise dos princípios de sustentabilidade e biossegurança aplicados ao estudo de caso}

Esta seção apresenta o resultado das análises comparativas entre os quesitos de sustentabilidade selecionados e os requisitos arquitetônicos necessários para garantir a biossegurança de edificações laboratoriais com classe de risco 3. Procura-se estabelecer um estudo a fim de compatibilizar as diretrizes para uma construção sustentável com as limitações impostas pela biossegurança.

As edificações laboratoriais de pesquisa em saúde têm diversas especificidades conforme seu uso e, para o atendimento simultâneo de diretrizes ambientais e de biossegurança, é necessário que os projetos sejam desenvolvidos de forma integrada e multidisciplinar (VIEIRA; SALGADO, 2008). Esses ambientes demandam uma visão de sequenciamento dos fluxos e cuidados com a segurança física pessoal, patrimonial e biológica. Normas regulamentadoras como as do Ministério do Trabalho, as Resoluções da Diretoria Colegiada (RDC) da Anvisa, de biossegurança, entre outras, são fundamentais na orientação desses projetos.

Os indicadores para projeto utilizados para essa análise estão apresentados no Quadro 7.

Integram o escopo mínimo da ferramenta com o acréscimo de mais quatro indicadores, que foram ativados por terem sido considerados importantes para a qualidade do serviço laboratorial: funcionalidade e eficiência, controlabilidade, optimização e manutenção do desempenho operacional. Em função da localização geográfica um quinto indicador foi acrescido em qualidade ambiental interna, temperatura e umidade relativa do ar, porém a ferramenta canadense não avalia o ruído interior, pois as normativas edilícias locais já o fazem.

Figura 5 - Detalhe de laboratório de pesquisa em saúde

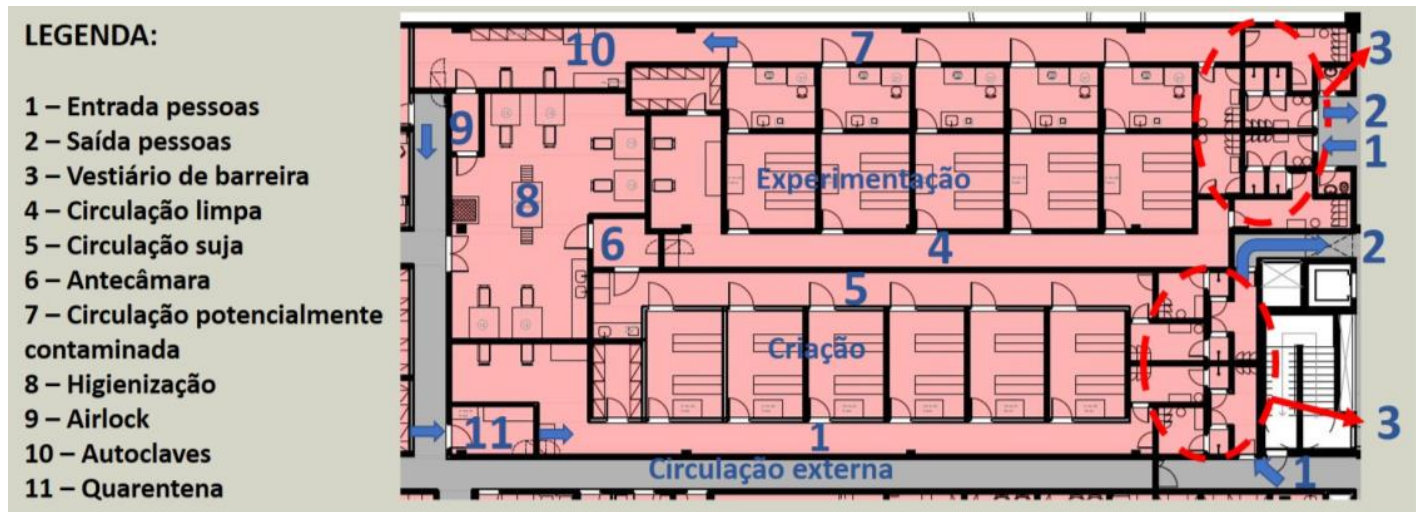

Fonte: adaptado de Fiocruz Minas (FUNDAÇÃO..., 2019).

${ }^{5}$ Biomodelos, genericamente, são animais experimentais, com características adequadas às pesquisas desenvolvidas (ANDRADE; PINTO; OLIVEIRA, 2002). 
Quadro 7 - Categorias e indicadores para projeto laboratorial

\begin{tabular}{|c|c|c|}
\hline \multicolumn{3}{|c|}{ INDICADORES SBTool PARA PROJETO - ESCOPO MÍNIMO } \\
\hline $\mathbf{A}$ & Recuperação do solo, desenho urbano e infraestrutura & 2 indicadores \\
\hline A1 & Desenho urbano & $\begin{array}{l}\text { Impacto da orientação no potencial } \\
\text { solar passivo da edificação }\end{array}$ \\
\hline $\mathrm{A} 2$ & Infraestrutura do projeto e serviços & $\begin{array}{l}\text { Provimento de sistema de gestão de } \\
\text { águas superficiais }\end{array}$ \\
\hline B & Consumo de energia e de recursos & 4 indicadores \\
\hline \multirow{2}{*}{ B1 } & \multirow{2}{*}{$\begin{array}{l}\text { Energia não renovável - Energia total: avaliação ciclo de } \\
\text { vida }\end{array}$} & $\begin{array}{l}\text { Consumo de energia renovável em } \\
\text { todas as operações da edificação }\end{array}$ \\
\hline & & $\begin{array}{l}\text { Consumo de energia não renovável em } \\
\text { todas as operações da edificação }\end{array}$ \\
\hline B2 & Uso de materiais & $\begin{array}{l}\text { Grau de reutilização de estruturas } \\
\text { existentes, quando existentes }\end{array}$ \\
\hline B3 & Uso de água potável, pluvial e cinza & $\begin{array}{l}\text { Uso de água para uso dos ocupantes } \\
\text { durante operação (uso) }\end{array}$ \\
\hline $\mathbf{C}$ & Cargas ambientais & 2 indicadores \\
\hline $\mathrm{C} 1$ & Emissão de gases de efeito estufa & $\begin{array}{l}\text { Emissões de energia primária ao usar as } \\
\text { futuras instalações }\end{array}$ \\
\hline $\mathrm{C} 2$ & Resíduos sólidos e líquidos & Resíduos sólidos e líquidos \\
\hline $\mathbf{D}$ & Qualidade ambiental interna & 2 indicadores \\
\hline D1 & Qualidade do ar interior e ventilação & Concentração de $\mathrm{CO} 2$ no ar interior \\
\hline D2 & Temperatura e umidade relativa do ar & Originalmente desativado $* *$ \\
\hline D3 & Luz natural e iluminação & $\begin{array}{l}\text { Luz natural adequada nas áreas de } \\
\text { ocupação primárias }\end{array}$ \\
\hline $\mathbf{E}$ & Qualidade do serviço & 2 indicadores \\
\hline \multirow{2}{*}{ E1 } & \multirow{2}{*}{ Segurança e proteção } & $\begin{array}{l}\text { Risco de incêndio para ocupantes e } \\
\text { instalações }\end{array}$ \\
\hline & & $\begin{array}{l}\text { Risco de enchente para ocupantes e } \\
\text { instalações }\end{array}$ \\
\hline $\mathrm{E} 2$ & Funcionalidade e eficiência & Originalmente desativado * \\
\hline E3 & Controlabilidade & Originalmente desativado * \\
\hline E4 & Flexibilidade e adaptabilidade & Originalmente desativado * \\
\hline E5 & Optimização e manutenção do desempenho operacional & Originalmente desativado * \\
\hline $\mathbf{F}$ & Percepção e aspectos socioculturais & 1 indicador \\
\hline $\mathrm{F} 1$ & Aspectos sociais & Acesso universal ao local e entorno \\
\hline $\mathbf{G}$ & Custo e aspectos econômicos & 1 indicador \\
\hline G1 & Custo e aspectos econômicos & Custo de construção \\
\hline
\end{tabular}

Fonte: Correia (2019).

Nota: *indicador SBTool acrescido ao escopo mínimo em função da sua importância para este uso específico.

**indicador originalmente desativado que foi acrescido ao escopo mínimo em função da localização geográfica.

Com o objetivo de avaliar os requisitos de sustentabilidade e de biossegurança no estudo de caso foi desenvolvida uma matriz de análise, apresentada no item a seguir.

\section{Matriz de análise}

Com base nas categorias do SBTool (linhas de 1 a 8) e nos aspectos arquitetônicos necessários para garantir níveis de biossegurança NB-3 (colunas de 1 a 9), o Quadro 8 exemplifica as análises.

Dessa forma, verificou-se o impacto das edificações laboratoriais segundo as áreas de análise de desempenho do SBTool e os resultados foram classificados como positivos (pos), neutros (nt) ou negativos (neg), conforme o impacto ambiental.

Foram considerados referências de emissão padrão e outros conteúdos desenvolvidos para o Canadá (benchmark original canadense). O sistema de referência e indicadores de avaliação também provêm do original canadense (em inglês), escopo de avaliação média. Tendo como base o escopo mínimo, 
adicionalmente foi ativado um requisito em função da localização geográfica e outros quatro requisitos importantes para laboratórios. Por outro lado, foram inativados os requisitos inadequados à nossa realidade, que, dessa forma, não interferiram nos resultados.

Considerou-se o projeto da nova edificação avaliada como ocupação de tipologia mista, que compreende escritórios, laboratórios e estacionamento. Foi utilizado um escopo de avaliação média. A edificação é composta de oito pavimentos, ou seja, os critérios para edifício alto (acima de 25 pavimentos) foram desabilitados. Assim como foram desabilitados os critérios das instalações para aquecimento ambiental, adequados para o clima canadense.

Para os ambientes administrativos foi habilitada como opcional a ventilação natural ou mecânica. Já nos espaços laboratoriais, para garantir a contenção de contaminantes, são de uso obrigatório: refrigeração, ventilação e exaustão mecânicas.

Na localização de um laboratório é importante considerar o risco de exposição na circunvizinhança na circulação de pessoas e animais, no transporte, no tratamento e descarte de rejeitos, nas emanações gasosas pelo sistema de filtração de ar. Por outro lado, os sistemas de controle de acidentes e de segurança patrimonial trazem benefícios ao entorno imediato (categorias 1 e 2).

Como exemplificado nas seções anteriores, em função da biossegurança inerente às atividades, o funcionamento diuturno dos equipamentos revela-se como essencial, o que acarreta importante consumo energético. É necessário o ajuste efetivo da vazão de ar das capelas de exaustão. A localização ideal delas em planta baixa também é um fator significativo de segurança, de forma a evitar turbulências de fluxo de ar, como indica Barbosa (2017).

\section{Quadro 8 - Matriz}

\begin{tabular}{|c|c|c|c|c|c|c|c|c|c|c|}
\hline & 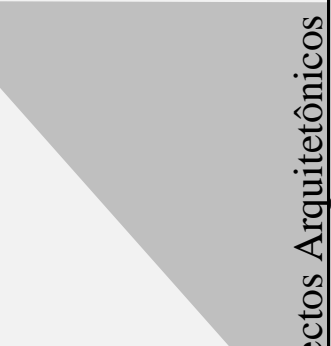 & 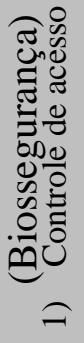 & 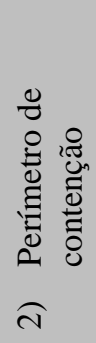 & 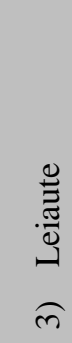 & 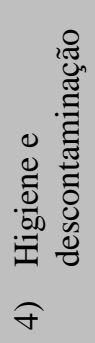 & 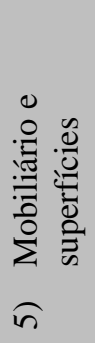 & 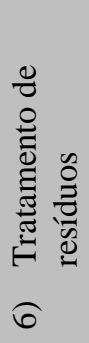 & 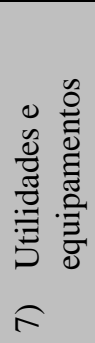 & 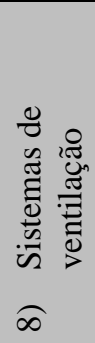 & 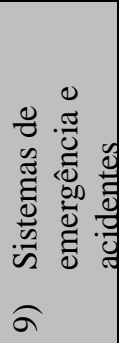 \\
\hline 1 & $\begin{array}{l}\text { Localização, } \\
\text { características loca1 } \\
\text { e serviços } \\
\text { disponíveis }\end{array}$ & $\mathrm{nt}$ & nt & nt & $\mathrm{nt}$ & $\mathrm{nt}$ & $\mathrm{nt}$ & $\mathrm{nt}$ & neg & pos \\
\hline 2 & $\begin{array}{l}\text { Recuperação do } \\
\text { solo, desenho urbano } \\
\text { e infraestrutura }\end{array}$ & pos & $\mathrm{nt}$ & nt & pos & $\mathrm{nt}$ & neg & $\mathrm{nt}$ & neg & pos \\
\hline 3 & $\begin{array}{l}\text { Consumo de energia } \\
\text { e de recursos }\end{array}$ & neg & neg & $\mathrm{nt}$ & neg & nt & neg & neg & neg & nt \\
\hline 4 & Cargas ambientais & nt & $\mathrm{nt}$ & $\mathrm{nt}$ & neg & neg & neg & neg & neg & $\mathrm{nt}$ \\
\hline 5 & $\begin{array}{l}\text { Qualidade ambiental } \\
\text { interna }\end{array}$ & neg & neg & $\mathrm{nt}$ & neg & neg & pos & neg & neg & neg \\
\hline 6 & Qualidade do serviço & nt & nt & nt & neg & pos & nt & pos & pos & $\mathrm{nt}$ \\
\hline 7 & $\begin{array}{l}\text { Percepção e aspectos } \\
\text { socioculturais }\end{array}$ & nt & pos & $\begin{array}{l}\mathrm{nt} / \\
\text { pos }\end{array}$ & pos & pos & pos & pos & pos & pos \\
\hline 8 & $\begin{array}{l}\text { Custo e aspectos } \\
\text { econômicos }\end{array}$ & neg & neg & neg & neg & neg & neg & neg & neg & neg \\
\hline
\end{tabular}

Fonte: Correia (2019).

Nota: Legenda:

\begin{tabular}{|c|}
\hline Neutro \\
\hline Positivo \\
\hline Negativo \\
\hline
\end{tabular}


Esse procedimento, por exemplo, tornou possível em um caso reduzir a vazão de ar, de $0,5 \mathrm{~m} / \mathrm{s}$ para $0,4 \mathrm{~m} / \mathrm{s}$, e assim economizar energia sem comprometer a biossegurança, fato que demonstra e comprova ser possível aliar qualidade técnica e eficiência energética ajustando especificações de projeto (David H. Koch. Institute for Integrative Cancer Research, MIT) (categorias 3 a 6).

Outra questão importante diz respeito à especificação de materiais de construção e de acabamento com menor carga ambiental, o que poderia atenuar o resultado negativo na matriz (categoria 4).

As barreiras por diferencial de pressão criadas pelo sistema de ventilação com uso de filtros HEPA permitem a sensação de segurança necessária e que pode explicar a avaliação positiva entre as categorias "SBTool (8) - sistemas de ventilação" e "aspectos arquitetônicos (7) - percepção e aspectos socioculturais dos usuários".

Os custos podem ser reduzidos (categoria 8) com a utilização de modulação e padronização das especificações, além de preferencialmente especificar equipamentos e materiais com durabilidade, facilidade e custos baixos de manutenção, incluindo a reposição de peças.

Ao examinar esses resultados observa-se que a classificação negativa alcança 43,05\% do total de avaliações para os requisitos, a classificação neutra varia entre $34,72 \%$ e $36,11 \%$ e a classificação positiva varia entre 20,83 e $22,22 \%$ do total, conforme variação perceptiva local das atividades de pesquisa (aspectos socioculturais). Os itens com avaliação negativa apresentam maior frequência, enquanto os itens com avaliação positiva são escassos.

Considera-se que há possibilidade de uma redução desses índices negativos, através de uma revisão de critérios e especificações de projeto, além do levantamento de informações aprofundadas sobre as pesquisas em saúde a serem realizadas nos espaços.

\section{Conclusões}

Os edifícios para comportar laboratórios de pesquisa em saúde devem ser concebidos, projetados e construídos em conformidade com os regulamentos edilícios, normas de biossegurança (conforme sua classificação de risco), atender a requisitos de sustentabilidade, como também a eficiência energética.

Quando as edificações são públicas deve ainda ser observado o atendimento a questões de licitações, economia e jurídicas.

Procurou-se na investigação realizada traçar um panorama sobre as condições exigidas pela legislação para assegurar condições adequadas de biossegurança em laboratórios de saúde, em termos de instalações, equipamentos e fluxos.

Após, considerou-se a análise da questão energético-ambiental por meio da utilização de procedimentos comerciais de certificação, em que se indica o alto custo envolvido no processo de certificação.

Em contrapartida investigou-se uma ferramenta gratuita com potencial de utilização, o SBTool, e com ela examina-se um projeto para edifício de laboratórios da Fiocruz em Belo Horizonte.

Verifica-se que, em função da condição exigida de biossegurança, há alguma implicação para atender a sustentabilidade e a eficiência energética em laboratórios de pesquisa em saúde.

É evidente que as instalações laboratoriais para pesquisa em saúde, em função da necessidade de atender à biossegurança, representam um alto investimento econômico e abrigam equipamentos onerosos. $\mathrm{O}$ funcionamento desses laboratórios demanda grande consumo de energia, o que se reflete nos impactos negativos apresentados na análise realizada.

Deve-se ainda considerar que a atividade de pesquisa em saúde em si oferece alto risco individual e coletivo, porém traz benefícios sociais em função dos avanços na medicina e cuidados com a saúde, daí a primordial importância da biossegurança nos laboratórios de pesquisa em saúde.

Apesar das limitações impostas pela biossegurança às questões de sustentabilidade, considera-se que alguma qualidade ambiental da edificação pode ser conseguida através da adoção de diretrizes projetuais adequadas.

Os melhores resultados seguramente virão com o emprego de critérios de projeto e metodologias de análise sobre o desempenho ambiental e do impacto da construção desde as fases de estudos preliminares, de desenvolvimento do projeto e ao longo do ciclo de vida da edificação. 


\section{Referências}

AGÊNCIA NACIONAL DA VIGILÂNCIA SANITÁRIA. Resolução - RDC Nº 69, de 08 dez. 2014, que dispõe sobre as Boas Práticas de Fabricação de Insumos Farmacêuticos Ativos. Diário Oficial da União, 09 dez. 2014.

ANDRADE, A.; PINTO, S. C.; OLIVEIRA, R. S. de (org.). Animais de laboratório: criação e experimentação. Rio de Janeiro: Editora Fiocruz, 2002.

ASSOCIAÇÃO BRASILEIRA DE NORMAS TÉCNICAS. NBR 10052: acústica: medições em campo de isolamento a ruído aéreo e de impacto e de sons de equipamentos prediais: método simplificado. Rio de Janeiro, 2020.

ASSOCIAÇÃO BRASILEIRA DE NORMAS TÉCNICAS. NBR 10520: informação e documentação: citações em documentos: apresentação. Rio de Janeiro, 2002.

ASSOCIAÇÃO BRASILEIRA DE NORMAS TÉCNICAS. NBR ISO 16283-1: acústica: medição de campo do isolamento acústico nas edificações e nos elementos de edificações: parte 1: isolamento a ruído aéreo. Rio de Janeiro, 2018.

BARBOSA, B. P. P. Análise da aerodispersão de contaminantes em laboratórios de pesquisa com biossegurança. Rio de Janeiro, 2017. 219 f. Tese (Doutorado em Engenharia Mecânica) - Escola de Educação, Universidade Federal do Rio de Janeiro, Rio de Janeiro. 2017.

BICALHO, F. de C. A Arquitetura e a engenharia no controle de infecções. Rio de Janeiro: Rio Books. 2010.

BRASIL. Constituição (1988), de 5 out. de 1988. Disponível em: http://www.planalto.gov.br/ccivil_03/Constituicao/Constituicao.htm. Acesso em: 26 fev. 2020.

BRASIL. Decreto 7.746, de 6 jun. de 2012. Disponível em: http://www.planalto.gov.br/. Acesso em: 10 mar. 2020.

BRASIL. Instrução Normativa n ${ }^{\circ}$, de 19 jan. 2010. Disponível em:

http://www.comprasnet.gov.br/legislacao/legislacaoDetalhe.asp?ctdCod=295. Acesso em: 26 jun. 2019.

BRASIL. Instrução Normativa $\mathbf{n}^{\circ}$ 2, de 2 jun. 2014, Disponível em:

http://pesquisa.in.gov.br/imprensa/jsp/visualiza/index.jsp?data=05/06/2014\&jornal=1\&pagina=102\&totalAr quivos=1641. Acesso em: 13 jul. 2017.

BRASIL. Instrução Normativa n ${ }^{\circ}$ 5, de 25 mai.2017. Disponível em: https://www.comprasgovernamentais.gov.br/index.php/legislacao/instrucoes-normativas/760-instrucaonormativa-n-05-de-25-de-maio-de-2017. Acesso em: 31 mai. 2018.

BRASIL. Lei no 8666, de 21 jun. de 1993. Disponível em: http://www.planalto.gov.br/ccivil_03/Leis/L8666compilado.htm. Acesso em: 26 jun. 2019.

BRASIL. Normas Regulamentadoras (NR). 1979 - 2019. Brasília: Ministério do Trabalho. Disponível em: https://enit.trabalho.gov.br/portal/index.php/seguranca-e-saude-no-trabalho/sst-menu/sst-normatizacao/sstnr-portugues?view=default. Acesso em: 21 out. 2019.

CORREIA, M. C. Avaliação da qualidade de projetos arquitetônicos de laboratórios públicos de pesquisa em saúde: sustentabilidade e biossegurança. Rio de Janeiro, 2019. 402 f. Tese (Doutorado em Arquitetura) - Escola de Arquitetura, Universidade Federal do Rio de Janeiro, Rio de Janeiro, 2019.

CORREIA, M. C.; LEAL, B. M. F. Avaliação do binômio sustentabilidade e biossegurança no desenvolvimento de projetos arquitetônicos de laboratórios de pesquisa médica na Fiocruz. In: ENCONTRO NACIONAL DE TECNOLOGIA DO AMBIENTE CONSTRUÍDO, 16., São Paulo, 2016. Anais [...] Porto Alegre: ANTAC, 2016.

CORREIA, M. C; SALGADO, M. S. HQE and its brand new sustainable reference framework challenges: a case study in FIOCRUZ, Brazil. In: CENTRAL EUROPE TOWARDS SUSTAINABLE BUILDING, 16. Praga, 2016. Proceedings [...] Praga, 2016.

COSTA, R. N. Qualidade ambiental em laboratórios biomédicos. Rio de Janeiro, 2011. 135 f.

Dissertação (Mestrado em Arquitetura) - Escola de Arquitetura, Universidade Federal do Rio de Janeiro, Rio de Janeiro, 2011. 
DIBERARDINIS, L. et al. Guidelines for laboratory design: Health, Safety, and Environmental Considerations. Hoboken: Willey, 2013.

DOMINGUEZ, B. Epidemia. Revista Radis, Rio de Janeiro, v. 210, mar. 2020.

FENILI, R. R. Boas práticas administrativas em compras e contratações públicas. Niteroi: Impetus, 2016.

FUNDAÇÃO OSWALDO CRUZ. Centro de pesquisa Rene Rachou. Minas Gerais. Disponível em: http:/www.cpqrr.fiocruz.br. Acesso em: 18 maio 2019.

FUNDAÇÃO OSWALDO CRUZ. Procedimentos para a manipulação de microorganismos patogênicos e/ou recombinantes na FIOCRUZ. Comissão Técnica de Biossegurança da FIOCRUZ. Manual. Nov. 2005. Rio de Janeiro. Disponível em: http://www.fiocruz.br/ctbio. Acesso em: 26 jun. 2019.

FUNDAÇÃO VANZOLINI. Certificação AQUA-HQE. Disponível em: http://vanzolini.org.br/aqua/certificacao-aqua-hqe/. Acesso em: 26 jun. 2019.

HAMILTON, D. K.; MCCUSKEY SHEPLEY, M. Design for critical care: an evidence-based approach. Abingdon: Routledge, 2016.

HAUTE QUALITE ENVIRONNEMENTALE. Relatório. Paris. 2015. Disponível em: http://www.behqe.com/. Acesso em: 8 maio 2016.

INTERNATIONAL INICIATIVE FOR A SUSTAINABLE BUILT ENVIROMENT. SB Method and SBTool. 2016. Disponível em: http://www.iisbe.org/sbmethod. Acesso em: 15 maio 2016.

LARSSON, N; BRAGANÇA, L. Using the SBTool System as a platform for education in sustainable built environment. 2016. Disponível em:

http://www.iisbe.org/system/files/SBTool\%20System\%20as\%20a\%20platform\%20for\%20education\%20in \%20SBE.pdf. Acesso em: 26 jun. 2019.

LARSSON, N. Part A, User Guide to the SBTool 2012 assessment framework. 2012. Disponível em: http://www.iisbe.org/node/140. Acesso em: 26 jun. 2019.

LARSSON, N. SBTool 2015 - overview 18Jul15. 2015. Disponível em: http://www.iisbe.org/sbmethod. Acesso em: 26 jun. 2019.

ORGANIZAÇÃO MUNDIAL DA SAÚDE. Manual de Biossegurança para Laboratórios da Tuberculose. Suíça, 2013.

ORGANIZAÇÃO MUNDIAL DE SAÚDE. Manual de segurança biológica em laboratório. 3. ed. Genebra, 2004.

PESSOA, C.; LAPA, R. Bioética e biorrisco: abordagem transdisciplinar. Rio de Janeiro: Interciência, 2003.

SALGADO, M. S. LEED CS in Brazil: discussing the validity of the method for the improvement of environmental quality on buildings. In: WORLD SUSTAINABLE BUILT ENVIRONMENT CONFERENCE, Hong Kong, 2017. Proceedings [...] Hong Kong, 2017.

SINDICATO DA INDÚSTRIA E DA CONSTRUÇÃO CIVIL DE MINAS GERAIS. Custo Unitário Básico - CUB. Belo Horizonte, 2019. Disponível em: http://www.sinduscon-mg.org.br/. Acesso em: 25 set. 2019.

SOUZA, A. D. S. Ferramenta ASUS: proposta preliminar para avaliação da sustentabilidade de edifícios brasileiros a partir da base conceitual da SBTool. Espírito Santo, 2008. Dissertação (Mestrado em Engenharia Civil) - Centro Tecnológico, Universidade Federal do Espírito Santo, Espírito Santo, 2008.

TEIXEIRA, P; VALLE, S. Biossegurança: uma abordagem multidisciplinar. Rio de Janeiro: Editora FIOCRUZ, 1996.

UNITED NATIONS. Report of the World Commission on Environment and Development: Our Common Future (WCED). 1987. Disponível em: http://www.un-documents.net/wced-ocf.htm. Acesso em: 26 jun. 2019.

VIEIRA, V.; SALGADO, M. S. Indicadores da Margem de Incerteza das decisões arquitetônicas para laboratórios NB3 a partir de estudo de casos. Gestão \& Tecnologia de Projetos, v. 3, n. 2, artigo nº 50943 , nov. 2008. 


\section{Agradecimentos}

Os autores agradecem o apoio da Fundação Oswaldo Cruz (Fiocruz) e da Coordenação de Aperfeiçoamento de Pessoal de Nível Superior - Brasil (Capes) - Código de Financiamento 001.

\section{Marcia Castilho Correia}

Coordenação Geral de Infraestrutura dos Campi | Fundação Oswaldo Cruz | Av. Brasil, 4365, Manguinhos | Rio de Janeiro - RJ - Brasil | CEP 21040-900 | Tel.: (21) 2209-2020 | Programa de Pós-Graduação em Arquitetura | Universidade Federal do Rio de Janeiro | Av. Pedro Calmon, 550, Sala 433, Ilha do Fundão | Rio de Janeiro - RJ - Brasil | CEP 21941-590 | Tel.: (21) 3938-0288 | E-mail: marciacorreia@ufrj.br

\section{Bianca Marques Figueiredo Leal}

Programa de Pós-Graduação em Arquitetura e Cidade | Universidade Federal do Rio de Janeiro | Tel.: (27) 3421-2137 | E-mail: bleal.arq@gmail.com

\section{Leopoldo Eurico Gonçalves Bastos}

Programa de Pós-Graduação em Arquitetura | Universidade Federal do Rio de Janeiro | Av. Pedro Calmon, 550, Sala 433, Ilha do Fundão Rio de Janeiro - RJ - Brasil | CEP 21941-590 | Tel.: (21) 3938-0288 | Programa de Pós-Graduação em Arquitetura e Cidade | Universidade Vila Velha | Av. Comissário José Dantas de Melo, 21, Boa Vista | Vila Velha - ES - Brasil | CEP 29102-920 | Tel.: (27) 3421-2137 | E-mail: leopoldobastos@gmail.com

\section{Ambiente Construído}

Revista da Associação Nacional de Tecnologia do Ambiente Construído

Av. Osvaldo Aranha, $99-3^{\circ}$ andar, Centro

Porto Alegre - RS - Brasil

CEP $90035-190$

Telefone: +55 (51) 3308-4084

Fax: +55 (51) 3308-4054

www.seer.ufrgs.br/ambienteconstruido

E-mail: ambienteconstruido@ufrgs.br

(c) (1)

This is an open-access article distributed under the terms of the Creative Commons Attribution License.

236 Correia, M. C.; Leal, B. M. F.; Bastos, L. E. G. 